\title{
Determinants of left ventricular function one year after cardiac transplantation
}

\author{
COLIN J REID, MAGDI H YACOUB \\ From Harefield Hospital, Middlesex
}

SUMMARY Left ventricular systolic function was assessed by radionuclide angiography in 107 consecutive transplant recipients who were alive one year after operation. Mean (SEM) ejection fraction was $62.4(4 \cdot 6)$ at rest and $68 \cdot 8(5 \cdot 4)$ on exercise. The influence of donor-related factors (donor age and sex, ischaemia time), recipient-related factors (recipient age and sex, frequency of acute rejection), type of immunosuppression (cyclosporin/azathioprine or prednisolone/azathioprine), and frequency of hypertension on left ventricular function one year after operation was examined by univariate and multivariate analysis. There was a close association both at rest and on exercise between a higher ejection fraction and treatment with cyclosporin/azathioprine. There was a trend for lower donor and recipient age, shorter ischaemia time, and fewer rejection episodes to be associated with better left ventricular function, but this was not statistically significant.

Left ventricular systolic function was well maintained in most patients a year after cardiac transplantation. The type of immunosuppression used had a strong influence on the left ventricular systolic function of the transplanted heart.

Cardiac transplantation has become established as an effective form of treatment for patients with severe myocardial disease. The one year survival is $75-$ $92 \%{ }^{1-4}$ and the quality of life of most of these patients is good. The late results of the operation are as yet not known. One of the main factors determining the longer term outcome of transplantation is left ventricular function, which can be influenced by several factors related to the donor or recipient or to the type. of immunosuppression used.

We have examined left ventricular function one year after transplantation and have assessed the possible influence of some of these factors.

\section{Patients and methods}

\section{STUDY GROUP}

We studied 107 consecutive recipients who were alive one year after transplantation and who had undergone operation between February 1980 and December 1984 (fig 1). Four patients were not available for study because they lived abroad. There

Requests for reprints to Dr Colin J Reid, Department of Cardiology, Royal Free Hospital, Pond Street, London NW3 2QG.

Accepted for publication 27 October 1987 were $101 \mathrm{men}$, and the age range of the group at the time of operation was $12-59$ (mean $44 \cdot 1$ ) years. An orthotopic operation had been performed in 93 $(87 \%)$ patients and a heterotopic one in $14(13 \%)$.

During this period, 155 patients had cardiac transplantation. There were 44 early $(<1$ year) deaths, $19 / 39(48 \cdot 7 \%)$ of those receiving prednisolone and azathioprine and 25/116 (21.5\%) of those on cyclosporin/azathioprine. The late mortality was $9 / 20(45 \%)$ in the prednisolone and azathioprine group (follow up 15-88 (mean 49.5) months) and $4 / 91(4.4 \%)$ in the cyclosporin and azathioprine group (follow up 22-57 (mean 36.6) months).

\section{RADIONUCLIDE VENTRICULOGRAPHY}

Left ventricular function was assessed by measurement of ejection fraction with gated radionuclide cineangiography at rest and on exercise. Red blood cells were labelled in vivo with $15 \mathrm{mCi}$ technetium- $99 \mathrm{~m}$. Images were acquired with an all purpose parallel-hole collimator and a gamma scintillation camera (Ohio-Nuclear). Studies were performed with the patient at rest in the supine position in a $40^{\circ}$ left anterior oblique projection. Symptom limited exercise was performed in a semi-supine position on a bicycle ergometer with an initial 


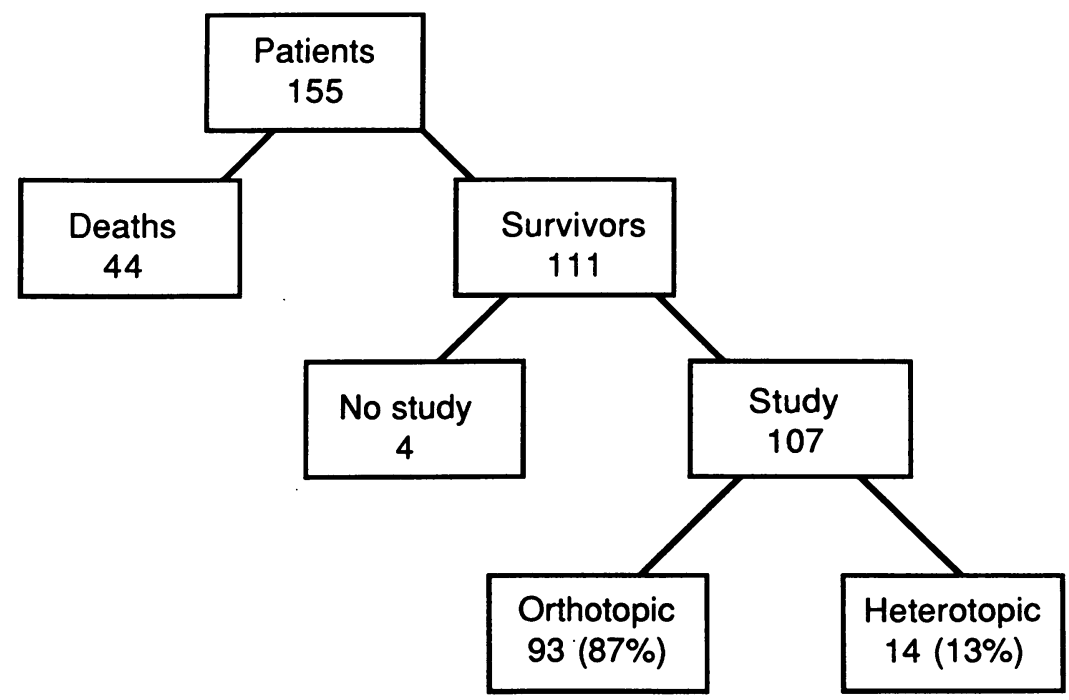

Fig 1 Study population of patients who had cardiac transplants between February 1980 and December 1984.

workload of $25 \mathrm{~W}$ and data were acquired over 10 minutes once a steady state had been reached. The ejection fraction was calculated by the multiple regions of interest method with computer-determined background areas. Exercise studies were not performed in heterotopic recipients in view of the difficulty in obtaining reliable electrocardiographic gating of the donor heart.

\section{VARIABLES}

Donor related

Donor age and sex.-Figure 2 shows the age distribu-

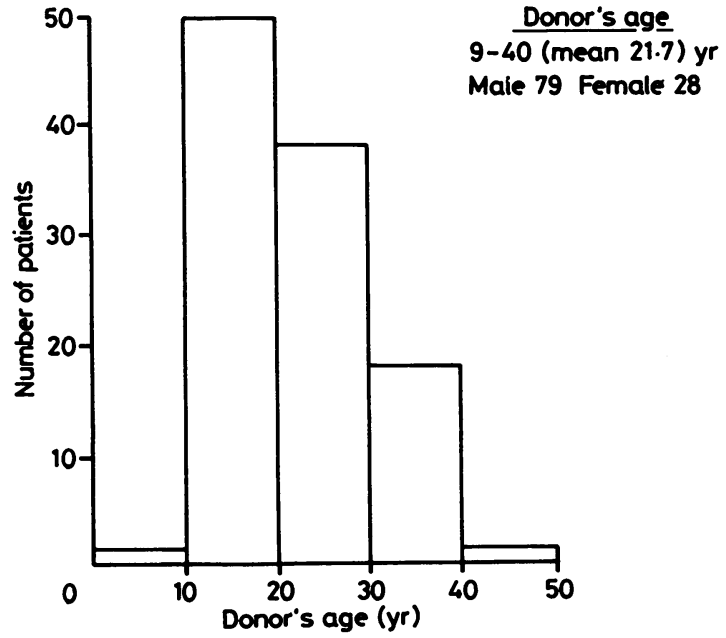

Fig 2 Distribution of ages of donors. tion of the donors. Donors were aged from 9 to 40 (mean 21.7$)$ years. There were $50(47 \%)$ donors below the age of $20,38(35 \%)$ between 20 and 30, 18 $(17 \%)$ between 30 and 40 , and $1(1 \%)$ aged 40 . Seventy nine $(74 \%)$ were male and twenty eight $(26 \%)$ female.

Ischaemia time.-The duration of the ischaemia time, defined as the time between clamping of the donor aorta and reperfusion of the donor heart in the recipient, varied from 70 to 300 (mean 138) minutes.

Table 1 shows the variation in ischaemia time.

\section{Recipient related}

Recipient age and sex.-The age range of the recipients was $12-59$ (mean $44 \cdot 1$ ) years (fig 3 ). Eighty five $(79 \%)$ patients were aged $\geqslant 40$ years at the time of transplantation. One hundred and one (94\%) recipients were male.

Acute rejection.-Table 2 shows the number of episodes of acute rejection in each patient in the first year after operation. A rejection episode was defined as one during which an endomyocardial biopsy

Table 1 Distribution of ischaemia time of donor hearts

\begin{tabular}{lc}
\hline $\begin{array}{l}\text { Ischaemia time } \\
\text { (min) }\end{array}$ & $\begin{array}{l}\text { No donors } \\
(\%)\end{array}$ \\
\hline $60-90$ & $7(6)$ \\
$90-120$ & $36(34)$ \\
$120-150$ & $25(24)$ \\
$150-180$ & $15(14)$ \\
$180-210$ & $12(11)$ \\
$210-240$ & $8(7)$ \\
$240-300$ & $4(4)$ \\
\hline
\end{tabular}




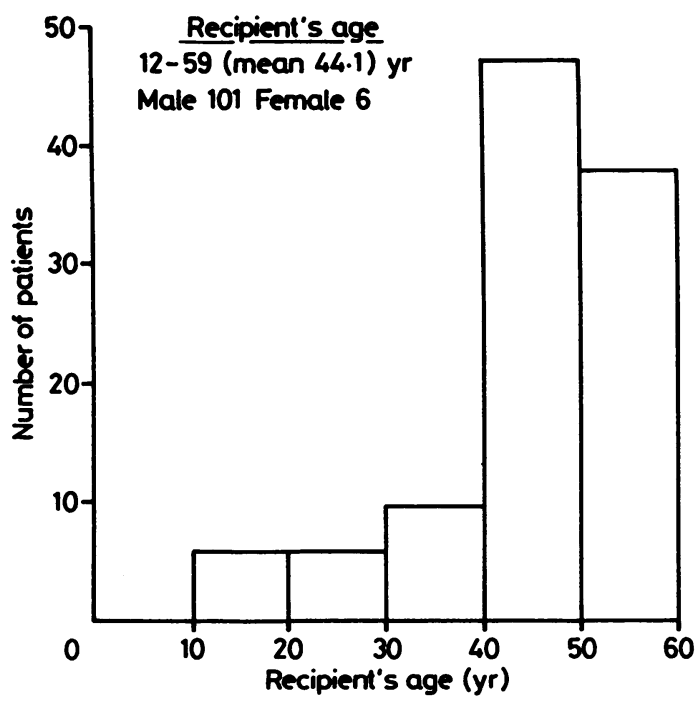

Fig 3 Distribution of ages of recipients.

specimen showed infiltration of interstitial, perivascular, or endocardial pyroninophilic mononuclear cells with or without myocytolysis. Patients were treated with methylprednisolone ( $1 \mathrm{~g}$ daily) for three days and/or antithymocyte globulin. The mean number of rejection episodes per patient during the first year after operation was $2 \cdot 7$.

\section{Immunosuppression}

A combination of oral steroids (prednisolone $1.5 \mathrm{mg}$ / $\mathrm{kg} /$ day, reducing to $0.5 \mathrm{mg} / \mathrm{kg} /$ day) and azathioprine $(2 \mathrm{mg} / \mathrm{kg} /$ day) was used as immunosuppression in the first $19(18 \%)$ patients in this study.

The next $88(82 \%)$ patients were given a combination of cyclosporin $(5-20 \mathrm{mg} / \mathrm{kg} /$ day) and azathioprine $(2 \mathrm{mg} / \mathrm{kg} /$ day $)$. Oral steroids were not routinely used in these patients.

\section{Hypertension}

Hypertension was defined as a blood pressure reading $\geqslant 145 / 90$ on two or more occasions during the first year. In the prednisolone and azathioprine group $2 / 19(11 \%)$ were hypertensive and in the cyclosporin and azathioprine group $24 / 55(44 \%)$ were hypertensive.

\section{Myocardial preservation}

St Thomas' cardioplegic solution, $20 \mathrm{ml}$ in 1 litre of normal saline introduced into the aortic root, was used for donor heart preservation in all cases. The hearts were then transported in Hartmann's solution at $4^{4} \mathrm{C}$.
Table 2 Occurrence of acute rejection in first year after transplantation

\begin{tabular}{lcc}
\hline No of episodes & No of patients & $\%$ \\
\hline 0 & 10 & 9 \\
1 & 20 & 18 \\
2 & 17 & 16 \\
3 & 35 & 33 \\
4 & 6 & 6 \\
5 & 11 & 10 \\
6 & 6 & 6 \\
7 & 1 & 1 \\
8 & 1 & 1 \\
\hline
\end{tabular}

\section{Statistical analysis}

Data were analysed by simple and multiple linear regression. The regression coefficient was obtained and $p$ value was determined. $P<0.05$ was regarded as significant.

\section{Results}

LEFT VENTRICULAR FUNCTION

The distribution of ejection fraction in the study group at rest (fig 4) and on exercise (fig 5) is shown. The ejection fraction was $60 \%$ in $75(70 \%)$ patients at rest and $79 \%$ patients on exercise. Left ventricular function was impaired (ejection fraction $<50 \%$ ) in $12(11 \%)$ patients at rest and three patients on exercise.

The mean (SEM) ejection fraction in a group of normal volunteers in our laboratory was $63(3.0) \%$ at rest and $71(2.3) \%$ on exercise. Pooled data on ejection fractions in the normal population from 28 centres world wide gave a value of $62.3(6 \cdot 1) \%$ at rest and $70.3(7 \cdot 6) \%$ on exercise. ${ }^{5}$

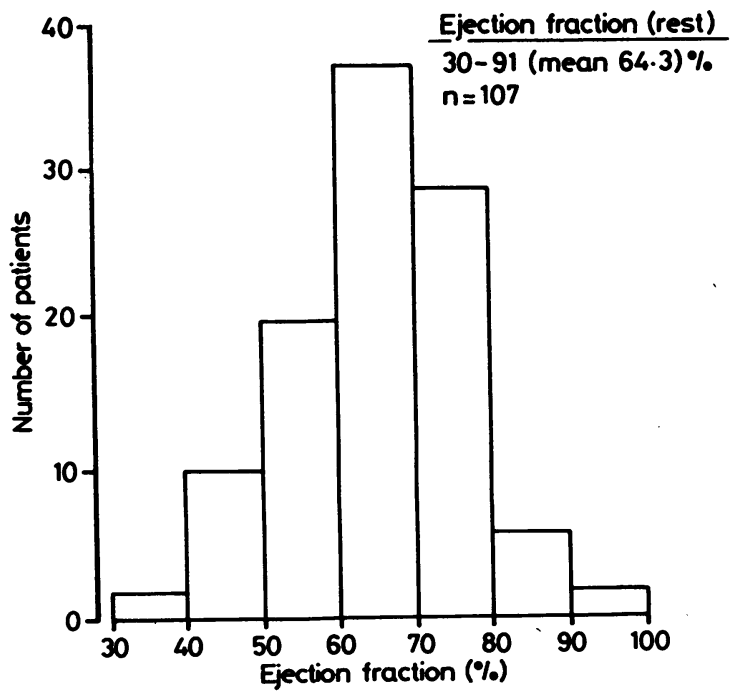

Fig 4 Range of ejection fraction of study group at rest. 


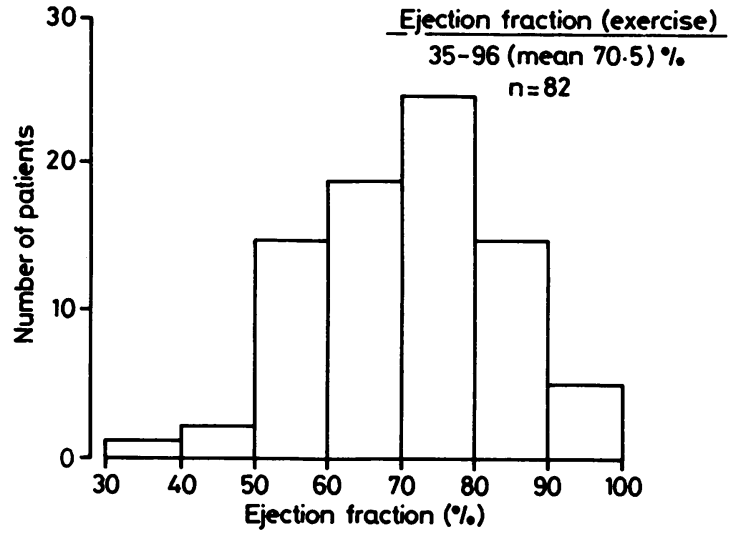

Fig 5 Range of ejection fraction of 82 patients undergoing exercise studies.

UNIVARIATE ANALYSIS (TABLE 3)

There was a significant association between treatment with cyclosporin and azathioprine and a higher ejection fraction at rest $(p<0.01)$ and on exercise $(p<0.001)$. Greater recipient age was associated with a lower ejection fraction at rest $(p<0.01)$ but not on exercise.

There was a trend for lower donor age, smaller number of rejection episodes, and shorter ischaemia time to be associated with improved ejection fraction both at rest and on exercise but the $95 \%$ confidence limit for this trend was not statistically significant.

\section{MULTIVARIATE ANALYSIS (TABLE 4)}

With multivariate analysis the association between treatment with cyclosporin/azathioprine and higher ejection fraction at rest and on exercise persisted $(\mathrm{p}<0.05$ and $\mathrm{p}<0.01$ respectively). No significant

Table 3 Evaluation of influence of variables on rest and exercise ejection fraction by univariate analysis

\begin{tabular}{lcrr}
\hline & $\begin{array}{l}\text { Regression } \\
\text { coefficient }\end{array}$ & t value & \multicolumn{1}{c}{$p$} \\
\hline & Rest & & \\
Cyclosporin & 7.84 & 2.71 & $<0.01$ \\
Recipient's age & -0.25 & -2.31 & $<0.01$ \\
Donor's age & -0.28 & -1.70 & $<0.10$ \\
Acute rejection & -1.05 & -1.61 & $<0.50$ \\
Donor's sex (M) & -3.40 & -1.34 & $<0.50$ \\
Ischaemia time & -0.16 & -0.66 & $>0.50$ \\
Recipient's sex (M) & 2.39 & 0.48 & $>0.50$ \\
& Exercise & & \\
Cyclosporin & 11.51 & 3.46 & $<0.001$ \\
Recipient's age & -0.08 & -0.60 & $>0.50$ \\
Donor's age & -0.29 & -1.38 & $<0.50$ \\
Acute rejection & -1.05 & -1.37 & $<0.50$ \\
Donor's sex (M) & 2.30 & 0.73 & $>0.50$ \\
Ischaemia time & -0.03 & -0.86 & $<0.50$ \\
Recipient's sex (M) & 1.41 & 0.24 & $>0.50$ \\
\hline
\end{tabular}

Table 4 Multivariate analysis of influence of variables on left ventricular function (ejection fraction)

\begin{tabular}{lcrl}
\hline & $\begin{array}{c}\text { Regression } \\
\text { coefficient }\end{array}$ & t value & \multicolumn{1}{l}{$p$} \\
\hline & Rest & & \\
Cyclosporin & 6.58 & 2.13 & $<0.05$ \\
Recipient's age & -0.20 & -1.71 & $<0.10$ \\
Donor's age & -0.12 & -0.69 & $<0.50$ \\
Acute rejection & -0.66 & -1.00 & $<0.50$ \\
Donor's sex (M) & -3.10 & -1.24 & $<0.50$ \\
Ischaemia time & -0.03 & -1.36 & $<0.50$ \\
Recipient's sex (M) & -1.71 & -0.34 & $>0.50$ \\
& Exercise & & \\
Cyclosporin & 11.36 & 3.08 & $<0.01$ \\
Recipient's age & 0.01 & 0.01 & $>0.50$ \\
Donor's age & -0.16 & -0.72 & $<0.50$ \\
Acute rejection & -0.31 & -0.40 & $>0.50$ \\
Donor's sex (M) & 2.47 & 0.80 & $<0.50$ \\
Ischaemia time & -0.03 & -1.04 & $<0.50$ \\
Recipient's sex (M) & 0.64 & 0.11 & $>0.50$ \\
\hline
\end{tabular}

association was demonstrated between resting or exercise ejection fraction and the other variables.

\section{SUBGROUP ANALYSIS}

Table 5 shows an examination of factors relating to patients with the lowest (group A) and highest (group B) ejection fractions.

Analysis of results confirmed that there is no significant difference between the distribution of factors apart from the type of immunosuppression used (table 6).

\section{IMMUNOSUPPRESSION：DISTRIBUTION OF VARIABLES}

Figure 6 shows the distribution of variables in the two immunosuppression treatment groups.

\section{Discussion}

Cardiac transplantation has become an effective therapeutic option in the management of end stage heart disease and can be performed with a low operative mortality and early postoperative mortality. The success of the procedure, however, will be determined by its ability to maintain normal cardiac performance both at rest and on exercise in the long term.

In this study, we measured left ventricular ejection fraction determined by radionuclide angiography because this technique is non-invasive and provides some information about changes on exercise. These variables, however, in common with all ejection phase indices, suffer the disadvantage of being loaddependent. In a previous study we showed that after transplantation, the inotropic state of the left ventricle determined by load-independent indices was normal. ${ }^{6}$ But this form of assessment of ventricular 
Table 5 Distribution of variables in patients with lowest ejection fractions (group $A$ ) and highest ejection fractions (group B)

\begin{tabular}{|c|c|c|c|c|c|c|}
\hline Case No & $\begin{array}{l}E F \% \\
\text { Rest Ex }\end{array}$ & $\begin{array}{l}\text { Recipient's } \\
\text { age/sex }\end{array}$ & $\begin{array}{l}\text { Donor's } \\
\text { age/sex }\end{array}$ & $\begin{array}{l}\text { Acute } \\
\text { rejection }\end{array}$ & $\begin{array}{l}\text { Ischaemia } \\
\text { time }\end{array}$ & $\begin{array}{l}\text { Immuno- } \\
\text { suppression }\end{array}$ \\
\hline $\begin{array}{c}\text { Group A: } \\
1 \\
2 \\
3 \\
4 \\
5 \\
6 \\
7 \\
8\end{array}$ & $\begin{array}{l}32(40) \\
39(35) \\
40(-) \\
41(55) \\
42(-) \\
43(55) \\
44(-) \\
45(54)\end{array}$ & $\begin{array}{l}47 \mathrm{M} \\
19 \mathrm{~F} \\
48 \mathrm{M} \\
46 \mathrm{M} \\
54 \mathrm{M} \\
51 \mathrm{M} \\
46 \mathrm{M} \\
50 \mathrm{M}\end{array}$ & $\begin{array}{l}25 \mathrm{M} \\
30 \mathrm{M} \\
39 \mathrm{~F} \\
16 \mathrm{M} \\
20 \mathrm{~F} \\
24 \mathrm{M} \\
23 \mathrm{~F} \\
18 \mathrm{M}\end{array}$ & $\begin{array}{l}6 \\
6 \\
4 \\
3 \\
3 \\
3 \\
3 \\
3\end{array}$ & $\begin{array}{r}110 \\
190 \\
150 \\
115 \\
255 \\
115 \\
90 \\
128\end{array}$ & $\begin{array}{l}\text { Pred/Aza } \\
\text { Cya/Aza } \\
\text { Cya/Aza } \\
\text { Cya/Aza } \\
\text { Cya/Aza } \\
\text { Cya/Aza } \\
\text { Pred/Aza } \\
\text { Pred/Aza }\end{array}$ \\
\hline $\begin{array}{c}\text { Group B: } \\
1 \\
2 \\
3 \\
4 \\
5 \\
6 \\
7 \\
8\end{array}$ & $\begin{array}{l}91(95) \\
91(90) \\
88(96) \\
88(95) \\
83(85) \\
83(-) \\
82(79) \\
80(80)\end{array}$ & $\begin{array}{l}36 \mathrm{~F} \\
43 \mathrm{M} \\
14 \mathrm{M} \\
53 \mathrm{M} \\
44 \mathrm{M} \\
34 \mathrm{M} \\
44 \mathrm{M} \\
48 \mathrm{M}\end{array}$ & $\begin{array}{r}22 \mathrm{M} \\
32 \mathrm{~F} \\
9 \mathrm{M} \\
35 \mathrm{M} \\
18 \mathrm{M} \\
36 \mathrm{M} \\
26 \mathrm{M} \\
19 \mathrm{M}\end{array}$ & $\begin{array}{l}3 \\
0 \\
3 \\
5 \\
1 \\
0 \\
5 \\
4\end{array}$ & $\begin{array}{r}99 \\
120 \\
125 \\
120 \\
157 \\
239 \\
80 \\
139\end{array}$ & $\begin{array}{l}\text { Cya/Aza } \\
\text { Cya/Aza } \\
\text { Cya/Aza } \\
\text { Cya/Aza } \\
\text { Cya/Aza } \\
\text { Cya/Aza } \\
\text { Cya/Aza } \\
\text { Cya/Aza }\end{array}$ \\
\hline
\end{tabular}

Aza, azathioprine; Cya, cyclosporin; Pred, prednisolone.

function could not be applied to the large numbers of patients in the current study and therefore the two studies cannot be compared directly.

We found that in most cases the systolic function of the transplanted heart, as determined by left ventricular ejection fraction at rest and on exercise, was well maintained one year after operation. These findings accord with other studies in which radionuclide angiography was used ${ }^{7} 8$ and with data from cardiac catheterisation one year after transplantation. ${ }^{910}$ Contrary to the findings of Devineni et al who saw no increase in ejection fraction on exercise in patients treated with cyclosporin, ${ }^{11}$ we noted a significant increase in ejection fraction on exercise $(72.5(1.4) \%$, compared with resting values $65.6(1 \cdot 2) \%)$ in the cyclosporin treated group. These results were significantly better than for those in patients treated with conventional immunosuppression $(61 \cdot 1(2 \cdot 5) \%, 57 \cdot 7(2 \cdot 7) \%$ respectively).

We found that the only factor that was significantly associated with improved left ventricular function both at rest and on exercise was treatment with cyclosporin. The cyclosporin and azathioprine patients were significantly younger $(43.4$ vs $47 \cdot 3 \mathrm{yr})$ and had fewer episodes of acute rejection $(2.50 \mathrm{vs}$ 3.73) in the first year after transplantation than patients given prednisolone and azathioprine. In addition, their left ventricular function was better despite a significantly longer ischaemia time $(142.5 \mathrm{vs}$ $118.2 \mathrm{~min}$ ) and a higher frequency of hypertension $(43.6 \%$ vs $10.5 \%)$. These factors assessed individually were not shown to exert significant influence upon ventricular function although there was a trend for younger donor and recipient age and, to a lesser extent, shorter ischaemia time and smaller number of rejection episodes to have a favourable influence on left ventricular function. Therefore, the mechanism by which cyclosporin exerts its beneficial effect on systolic function has not been defined. Despite examination of the distribution of variables in patients with the highest and lowest ejection fractions, no factor other than the type of immunosuppression used was identified as being an important determinant of ventricular function.

This work is part of a continuing programme to evaluate the long term results of cardiac transplantation. It is hoped that the information provided will help in optimising the results of this procedure.

Table 6 Comparison of ejection fraction (mean (SEM)) and values of variables (mean (SEM)) between group $A$ and group $B$

\begin{tabular}{|c|c|c|c|c|c|c|}
\hline & $E F^{\circ} \%$ & $\begin{array}{l}\text { Recipient's } \\
\text { age }\end{array}$ & $\begin{array}{l}\text { Donor's } \\
\text { age }^{\star}\end{array}$ & $\begin{array}{l}\text { Acute } \\
\text { rejection }\end{array}$ & $\begin{array}{l}\text { Ischaemia } \\
\text { time }\end{array}$ & $\begin{array}{l}\text { Immuno- } \\
\text { suppression }\end{array}$ \\
\hline Group A & $40 \cdot 7(1.44)$ & $45 \cdot 2(3.80)$ & $24 \cdot 4(2 \cdot 60)$ & $3.87(0.48)$ & $144 \cdot 1(19 \cdot 2)$ & \multirow{2}{*}{$\begin{array}{l}\text { Cya/Aza 5, Pred/ } \\
\text { Aza } 3 \\
\text { Cya/Aza 8, Pred/ } \\
\text { Aza } 0\end{array}$} \\
\hline Group B & $85.7(1.51)$ & $39 \cdot 5(4 \cdot 20)$ & $24 \cdot 6(3.37)$ & $2.62(0.73)$ & $134 \cdot 8(17 \cdot 0)$ & \\
\hline
\end{tabular}

\footnotetext{
*There was no significant difference between groups $A$ and $B$ for any of these variables.
} 

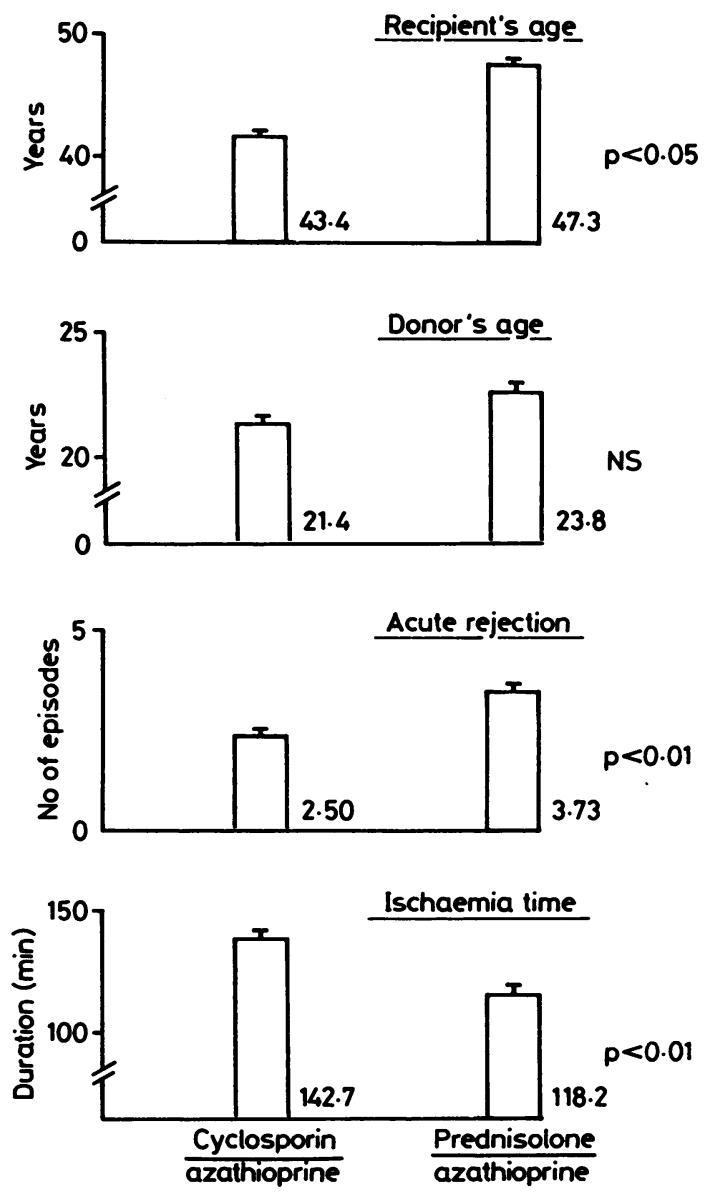

Fig 6 Distribution of variables in groups treated with cyclosporin/azathioprine or prednisolone/azathioprine.

\section{References}

1 Shumway NE. Recent advances in cardiac transplantation. Transplant Proc 1983;15:1221-4.

2 Solis E, Kaye MP. The Registry of the International Society for Heart Transplantation: third official report - June 1986. Heart Transplant 1986;5:2-15.

3 Yacoub MH, Reid CJ, Al-Kadimi RA, Radley-Smith R. Cardiac transplantation - the London experience. $Z$ Kardiol 1985;74(suppl 6):48-50.

4 Bolman RM, Olivari MT, Saffitz J, et al. Current results with triple therapy for heart transplantation. Transplant Proc 1987;19:2490-4.

5 Pfisterer ME, Battler A, Zaret BL. Range of normal values for left and right ventricular ejection fraction at rest and during exercise assessed by radionuclide angiocardiography. Eur Heart J 1985;6:647-55.

6 Borow KM, Neumann A, Arensman FW, Yacoub M. Left ventricular contractility and contractile reserve in humans after cardiac transplantation. Circulation 1985;71:866-72.

7 McGriffin DC, Karp RB, Logic JR, Tauxe WN, Ceballos R. Results of radionuclide assessment of cardiac function following transplantation of the heart. Ann Thorac Surg 1984;37:382-6.

8 Kemkes BM, Reichenspurner H, Osterholzer M, et al. First pass radionuclide scintigraphy for long-term follow-up after heart and heart-lung transplantation. Transplant Proc 1987;19:2543-5.

9 Greenberg ML, Uretsky BF, Reddy PS, et al. Longterm haemodynamic follow-up of cardiac transplant patients treated with cyclosporin and prednisolone. Circulation 1985;71:487-94.

10 Schroeder JS. Haemodynamic performance of the human transplanted heart. Transplant Proc 1979; 11:304-8.

11 Devineni R, McKenzie N, Kostuk WJ. Cyclosporin in cardiac transplantation: observations on immunologic monitoring, cardiac histology and cardiac function. Heart Transplant 1983;2:219-23. 